\title{
Polysaccharide-based Supramolecular Hydrogel for Efficiently Treating Bacterial Infection and Enhancing Wound Healing
}

\author{
Jing Wang, ${ }^{1,2}$ Li Feng, ${ }^{2}$ Qilin $\mathrm{Yu}^{3}{ }^{3}$ Yong Chen, ${ }^{1,2 *}$ and $\mathrm{Yu} \mathrm{Liu}^{2 *}$ \\ ${ }^{1}$ Tianjin Enterprise Key Laboratory for Application Research of Hyaluronic Acid, Tianjin, \\ China. ${ }^{2}$ College of Chemistry, Nankai University, Tianjin 300071, China. ${ }^{3}$ Key Laboratory \\ of Molecular Microbiology and Technology, College of Life Sciences, Nankai University, \\ Tianjin 300071, China.
}




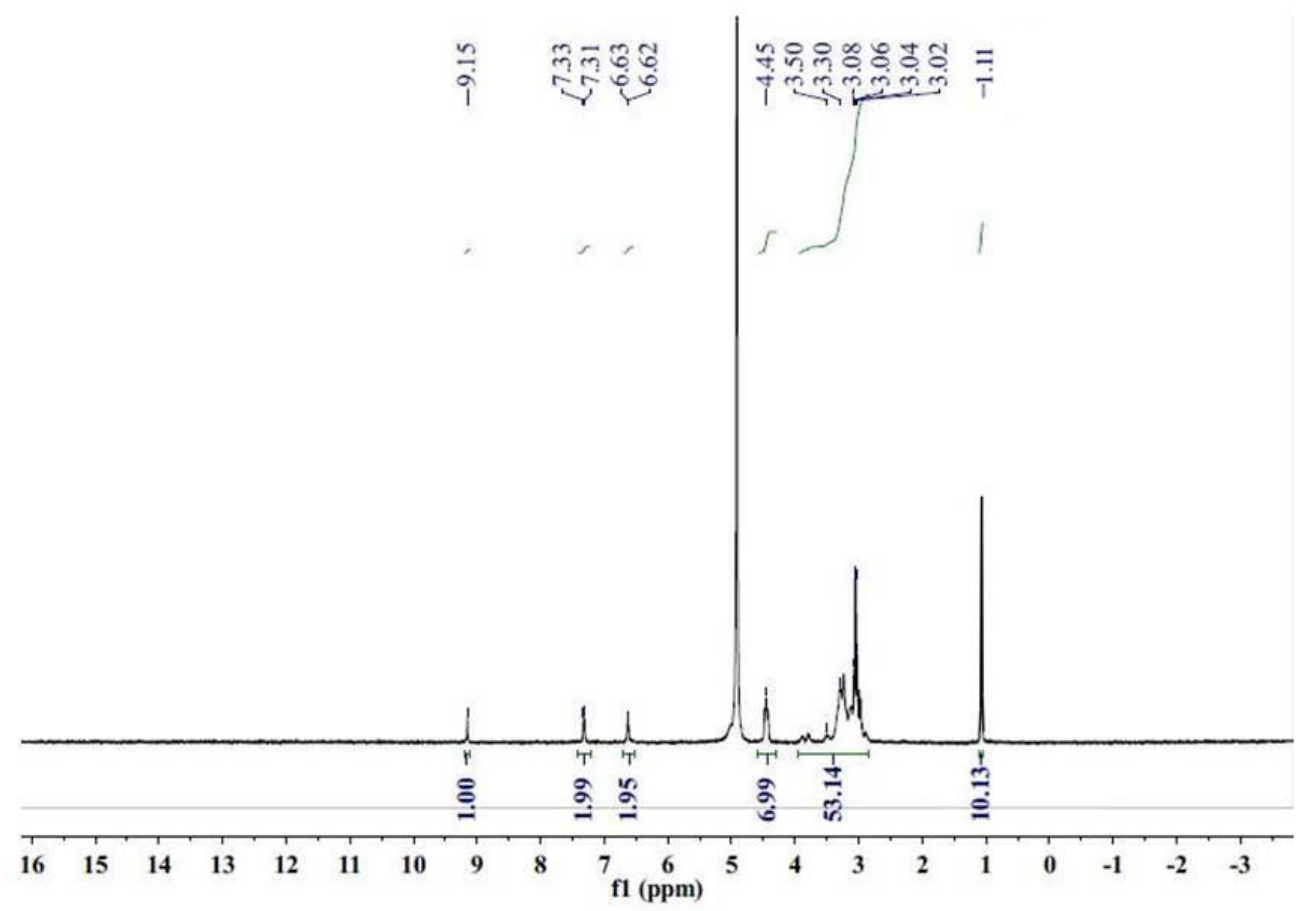

Fig. S1. ${ }^{1} \mathrm{H}$ NMR spectrum $\left(400 \mathrm{M}, 1 \mathrm{~mol} / \mathrm{L} \mathrm{DCl}\right.$ in $\left.\mathrm{D}_{2} \mathrm{O}\right)$ of CS-CD.

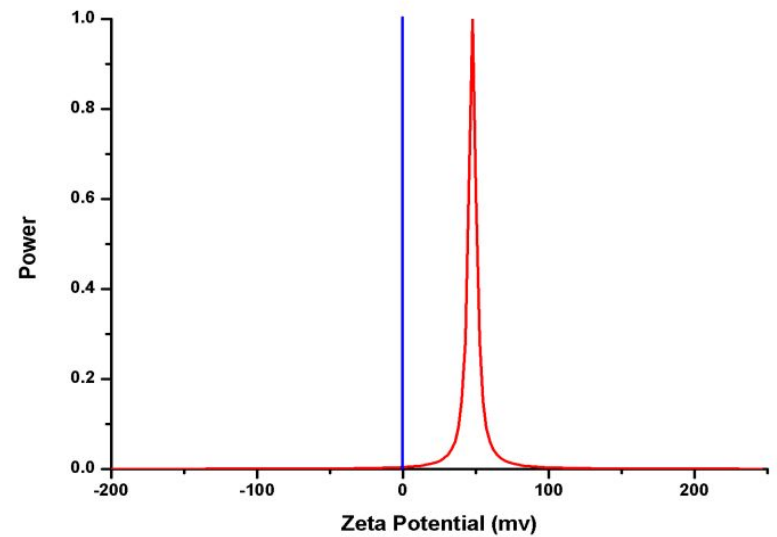

Fig. S2. Zeta potential of supramolecular hydrogel at $25^{\circ} \mathrm{C}$. 


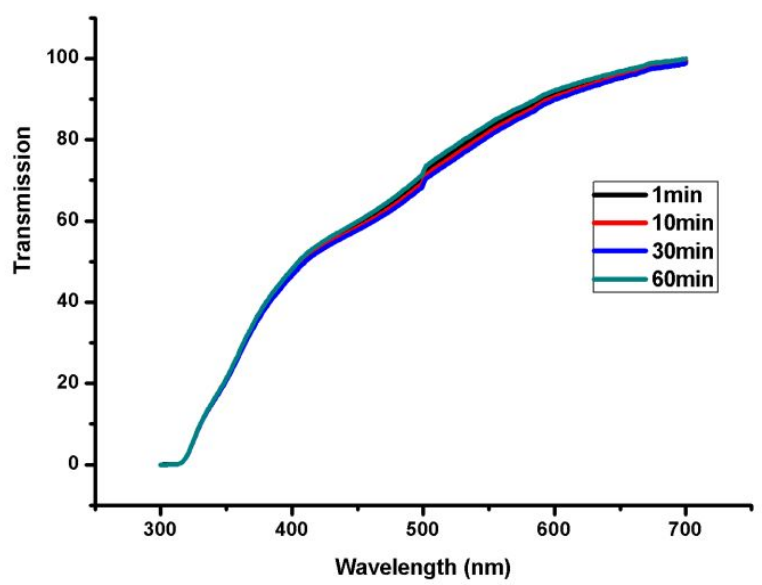

Fig. S3. The time-dependent transmission study of supramolecular hydrogel.

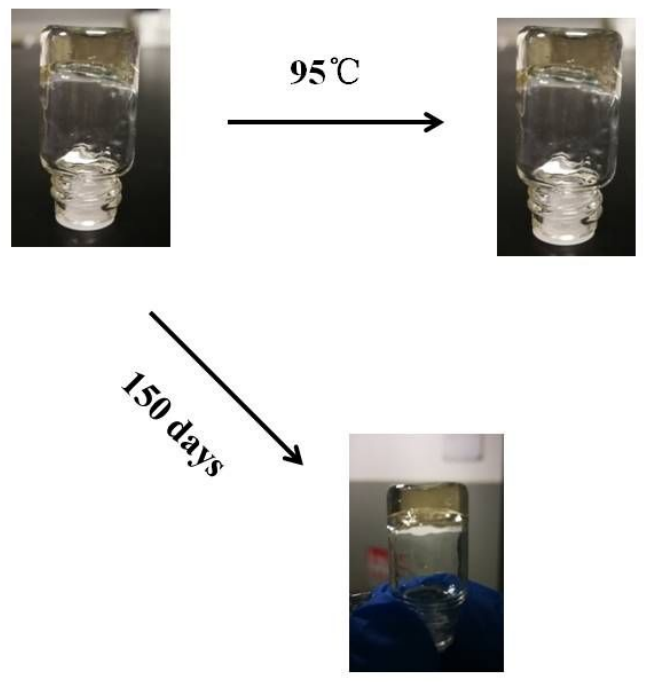

Fig. S4. The thermal stabilities and long-term stabilities of supramolecular hydrogel. 

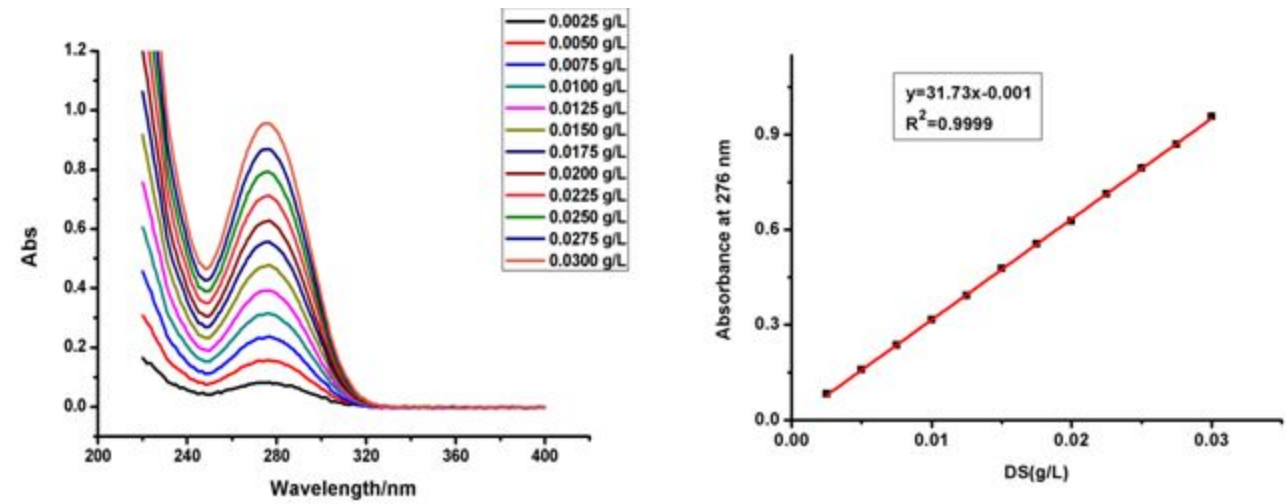

Fig. S5. (a) UV-vis spectra of DS aqueous solution under different concentrations. (b)

Standard curve of DS aqueous solutions under different concentrations.

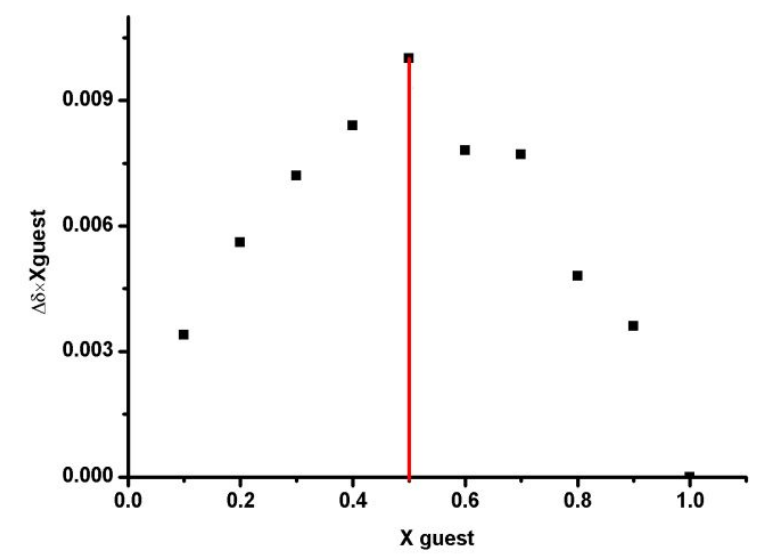

Fig. S6. Job's plots $\mathrm{DS} \subset \beta$-CD complexation in aqueous solution at $25^{\circ} \mathrm{C}$. 